\title{
Integrating Engineering and Arts through Capstone Design: Creative Cam- pus Meets the Learning Factory
}

\section{Prof. Timothy W. Simpson, Pennsylvania State University, University Park}

Timothy W. Simpson is a Professor of Mechanical and Industrial Engineering at Penn State with affiliate appointments in Engineering Design and the College of Information Sciences and Technology. As the Director of the Learning Factory, he coordinated 150 industry-sponsored senior design projects each year for over 700 students in the College of Engineering. He also serves as the Director of the Product Realization Minor. His research interests include product family and product platform design, trade space exploration and multi-dimensional data visualization, and multidisciplinary design optimization, and he has co-authored over 200 peer-reviewed journal and conference papers to date. He is the recipient of the 2011 ASEE Fred Merryfield Design Award and has received numerous awards for outstanding teaching and research, including the 2007 Penn State University President's Award for Excellence in Academic Integration. He is a Fellow in ASME and an Associate Fellow in AIAA. He received his Ph.D. and M.S. degrees in Mechanical Engineering from Georgia Tech, and his B.S. in Mechanical Engineering from Cornell University.

\section{Mr. Marcus Shaffer, Penn State Architecture}

Marcus Shaffer's research focuses on works, theories, and practices that engage the Machine as an architectural extension of our impulse to examine and re-make the natural world. This work includes building machines, automatons, and spiritual mechanisms that represent our earliest technological expression; the mechano-pagan influence of the Machine on modern/visionary architecture; and attempts to embody architectural knolwedge and craft in construction/fabrication technologies. As a designer and studio critic experienced with industrial and handcrafted means of making, he addresses architecture not only as the manifestation of our physical needs and cultural desires, but also as constructed form directly resultant from the combination of mind, machinery, materials, and process/labor. While Marcus studies and contributes to a critical discourse probing and defining the Machine in an architectural context, his historical/theoretical search is informed by, and applied to the design and fabrication of various Tectonic Machines. The agenda for these machines is a synthesis of our powerfully rationalized technologies with the potency of meaning found in our ritual practices - which includes building. Prof. Shaffer has a BFA in Industrial Design from the Rhode Island School of Design, and an M. Arch from Virginia Polytechnic Institute and State University.

\section{Mrs. Elisha Clark Halpin, Penn State University, School of Theatre, Dance Program}

Elisha Clark Halpin is an Associate Professor and Head of Dance at Penn State. She is the artistic director of ETCH Dance Co. Her choreographic investigations concentrate on the body as text: using autobiography, ethnicity, and identity as ways to generate movement, develop context, and construct metaphors in contemporary dance. Elisha was an Emerging Choreographer at the Bates Dance Festival. Her work, How Frail the Human Heart, was awarded "Best Dance" at the 2010 Capital Fringe Festival. Her latest work, the sky is empty, was commissioned by Dance New Amsterdam. Elisha graduated with an M.F.A in performance and choreography from The Ohio State University and a B.F.A in dance and theatre from the University of Memphis. Elisha has been on the faculty of Ohio State, Wittenberg University, Columbus Youth Ballet, Memphis Dance Group, and the professional training program at Dublin Dance Center. She has been a guest artist at Radford University, Kenyon College, Fort Hayes Arts High School, Wharton Middle School for the Arts, Columbus Movement2, SUNY Buffalo, and SUNY Brockport. ETCH, formed in 2008, creates work that is evocative, starkly honest, and kinesthetically driving. The movement is highly athletic and intense, utilizing traditional dance technique as the foundation to push the limits of structure in time and space. Investigating autobiography, ethnicity, and identity through movement weaves vulnerability with a range of emotional experiences to build a powerful energy that propels the work. Halpin's choreography delves into the female identity while showcasing the intricacies of the body on a visceral level. www.etchdance.org 


\section{Mrs. Amy Dupain Vashaw, Center for the Performing Arts @ Penn State}

AMY DUPAIN VASHAW serves as Audience and Program Development Director for Penn State University's Center for the Performing Arts, a position she has held since 2001. Initially hired as Education Director in 1997, her primary responsibility is the creation of programs which link the artists on the Center's season to various facets of the community, including Penn State University students, students in grades $\mathrm{K}-12$, senior members of the community, and the community-at-large. Her primary goal is to create a mutually enriching experience for both artists and their audiences by providing the knowledge and tools necessary to fully engage in the artist's work. Additionally, she works closely with the Center director in programming the season, with her special area of focus being family and children's programming. She has served as president of Pennsylvania Presenters, a statewide presenting consortium. She is also the advisor to Orchesis Dance Company, a student dance company which produces two concerts a year, comprised solely of member-choreographed works. She is a graduate of Penn State University with a degree in cinema studies.

\section{Dr. Dorothy H. Evensen, Pennsylvania State University, University Park}

Dorothy H. Evensen is a Professor of Education at Penn State University where she teaches courses on qualitative research, college curriculum and teaching, and legal issues in higher education. She earned a doctorate in educational psychology from New York University in 1991 and her dissertation examined reading strategies used by first-year law students. Since then, Professor Evensen has investigated various areas within legal education including study groups, students' case reading skills, academic support programs, and, most recently, issues of access among African Americans. Besides law, she has conducted research in other professional areas such as medicine, engineering, and teacher education. Her research work has received funding from the Law School Admissions Council, the National Science Foundation, the Spencer Foundation, and the U.S. Department of Education. 


\title{
Integrating Engineering and Arts through Capstone Design: Creative Campus Meets the Learning Factory
}

\begin{abstract}
The Learning Factory at Penn State coordinates the largest college-wide, industry-sponsored engineering capstone design program in the country. Each year, over 750 engineering students across 12 different majors work in teams of 4-6 for a semester on industry- and client-sponsored capstone design projects. About $30 \%$ of these projects engage students in a single engineering discipline (e.g., mechanical engineering), 40\% engage students in two disciplines (e.g., chemical engineering and mechanical engineering), and 30\% engage students in three or more disciplines (e.g., bioengineering, electrical engineering, and industrial engineering). As the capstone program grew across disciplines within engineering, it also enabled teams to work with students and faculty outside of engineering. Based on the needs of a specific project, an engineering capstone design team can now be paired with students in one or more of the following colleges: Arts \& Architecture, Business, Communications, Earth \& Mineral Sciences, Health \& Human Development, or Information Sciences \& Technology. The result is an interdisciplinary experience that is more representative of what students will find in the real world. In this paper, we share our experiences using capstone design projects to integrate students and faculty in engineering and arts as part of a two-year Creative Campus project, The Secret Life of Public Spaces. An overview of the Creative Campus initiative is provided along with details on our specific project and the three capstone design projects that supported it. The perceptions of the faculty "clients" for each capstone project are discussed along with relevant feedback that was obtained as part of the overall project assessment. While tensions among the engineering and non-engineering students and faculty "clients” ran high at times, two of the three capstone design projects were recognized with Best Project awards at the end of the semester showcase as judged by experts from industry, evidence of the benefits of working across multiple disciplines.
\end{abstract}

\section{Introduction: Capstone Design Projects at the Learning Factory}

Capstone design programs vary widely across the United States as engineering departments at institutions find subtly different ways of blending their internal academic culture with external industry and client participation to create meaningful "culminating experiences" that strive to satisfy usually numerous ABET criteria. ${ }^{1,2}$ Some capstone programs rely heavily on industry sponsors and clients while others leverage design competitions (e.g., Formula $\mathrm{SAE}^{3}$ ) to create capstone projects for their students. Some capstone design experiences last only a semester while others last a year or longer; some capstone projects run in parallel to instruction while others run separately. ${ }^{1}$ Meanwhile, some capstone design projects only engage students in a single discipline while others work across multiple departments and colleges to engage students from multiple engineering and non-engineering disciplines to infuse "real world" experiences into capstone design, in particular, and engineering education, in general. ${ }^{4}$

At Penn State University, the Learning Factory helps coordinate the capstone design program across 12 different engineering majors. Founded in 1995, the Learning Factory was established with a $\$ 2.75 \mathrm{M}$ grant from the ARPA/NSF Technology Reinvestment Program in Manufacturing Engineering Education to Penn State, University of Puerto Rico-Mayaguez, and the University 
of Washington in partnership with Sandia National Laboratories. ${ }^{5}$ Winner of the 2006 National Academy of Engineering's Gordon Prize for Engineering Education, ${ }^{6}$ the partners developed shared curriculum materials and degree options in product realization or manufacturing to help bring real-world experiences into the engineering classroom. For capstone design in particular, the Learning Factory fosters university-industry partnerships whereby industrial sponsors and clients interact with students and faculty through hands-on capstone design projects. Initially, these projects primarily engaged mechanical engineering, industrial engineering (manufacturing track), and electrical engineering students at Penn State; however, the program has expanded significantly over the past five years to serve numerous departments and engage over 750 students each year. ${ }^{7}$ The program is self-sustaining through a combination of industry, college, and department support and was recently recognized as one of six programs in the world to achieve sustainable innovation in engineering education. ${ }^{8}$

Capstone design projects coordinated by the Learning Factory run for a single semester (15 weeks) and typically engage a team of 4-6 engineering students. The semester begins with a Project Kickoff during the first week of classes wherein industry sponsors and clients participate in a "trade show" type event to field questions about the projects being offered. All of the students will have reviewed the available project descriptions prior to the Project Kickoff, and by the end of the event, they must submit their top five project preferences. Students can select any project that requires their discipline, which is indicated in the project description and confirmed by faculty prior to the Project Kickoff. Faculty from all of the participating departments meet immediately after the Project Kickoff and assign students to teams based on their preferences, schedule availability, and project scope and disciplinary needs. Teams are notified, and students are subsequently transferred into the appropriate department section. Teams contact their sponsor in the second week of the semester, arrange a site visit or plant tour (if needed), and start reviewing the project in more detail with the sponsor. Patent searches, literature reviews, customer needs assessment, benchmarking, etc. are then performed as needed, and sponsors receive weekly updates from the team followed by a 15-30 minute teleconference to provide technical support and guidance. Teams then design, analyze, model, prototype, test, etc. for the remaining weeks to satisfy the scope of their project. The team prepares a detailed project proposal (i.e., Statement of Work) and presentation for the sponsor by Week 6 of the semester, a detailed system design report by Week 10, and a final report (and presentation) during Week 15, which is also when the Design Showcase is held.

At the Design Showcase, all of the capstone teams display their project results along with a poster as shown in Figure 1. Teams are judged by industry representatives who provide awards and cash prizes for Best Project $\left(1^{\text {st }}, 2^{\text {nd }}\right.$, and $3^{\text {rd }}$ place $)$ and Best Poster $\left(1^{\text {st }}, 2^{\text {nd }}\right.$, and $3^{\text {rd }}$ place $)$. Faculty supervise the teams and meet with them twice per week: (1) one-on-one with each team for 30 minutes, and (2) with all the teams together for a 75-minute class session, during which time the instructor lectures, has guest speakers, conducts group activities, etc. as warranted. A faculty member usually supervises 5-6 teams (25-30 students) per section of the capstone design course, which counts toward their teaching load. Course syllabi, report templates, grading rubrics, project sponsorship, and judging criteria can all be found online on the Learning Factory’s website (www.lf.psu.edu). 


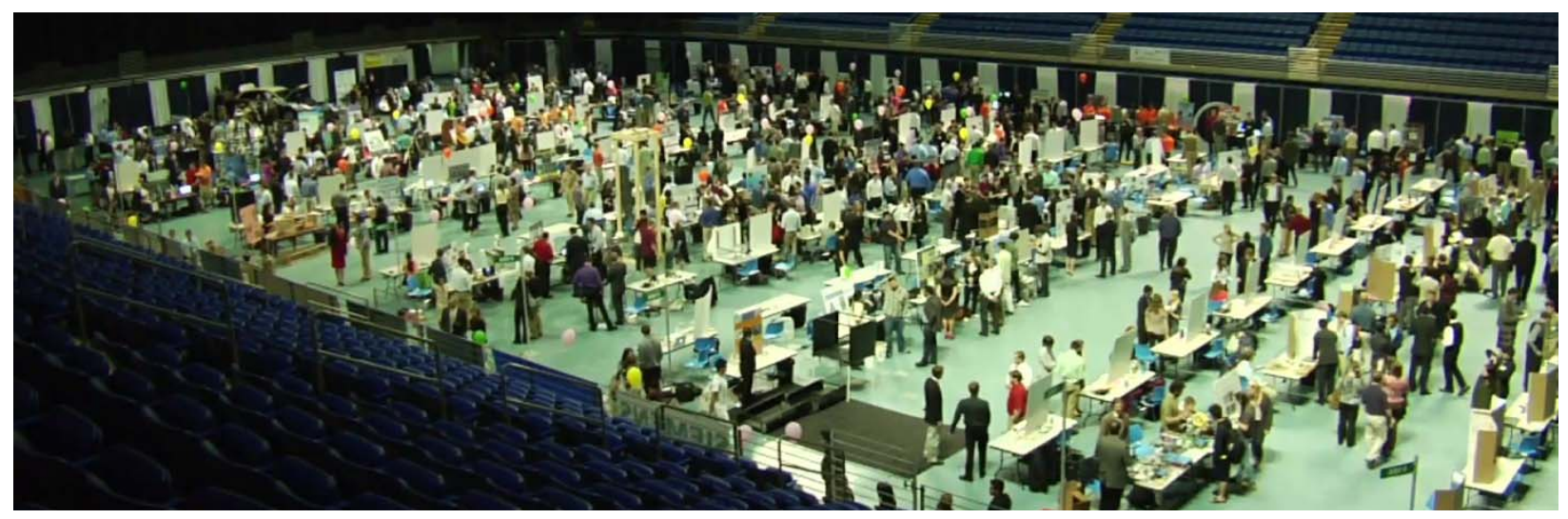

Figure 1. Spring 2012 Design Showcase Featured 165 Design Projects (94 Capstone)

In Spring 2010, a multidisciplinary capstone design section was established by Penn State's School of Engineering Design, Technology, and Professional Programs (SEDTAPP) to accommodate capstone projects that need three or more disciplines (e.g., design projects from entrepreneurs and start-up firms ${ }^{7}$ ). The Learning Factory helped ensure that ABET requirements were satisfied across all participating departments, enabling students to transfer between capstone courses in different departments. In some instances, departments pushed some of their ABET criteria from the capstone design course into lower-level courses to enable students to swap sections. As a result, about $30 \%$ of the capstone design projects each semester now engage students in a single discipline (e.g., mechanical engineering), 40\% engage students in two engineering disciplines (e.g., chemical engineering and mechanical engineering), and 30\% engage students in three or more disciplines (e.g., bioengineering, electrical engineering, and industrial engineering).

As the capstone design program has grown to encompass more disciplines in engineering, it has also expanded beyond engineering to enable partnerships with students in other colleges. By working closely with the corresponding "capstone coordinators" in other colleges, cross-college teams can now be fielded as projects warrant. For example, a team of engineering students developing a prototype for an entrepreneur as part of their capstone project may partner with a team of business students who develop a business plan for the same sponsor, or engineering students might work with a team of students in Information Science and Technology (IST) to create use cases and develop specifications for a new product data management system for an industry sponsor. While this is by no means unique the Learning Factory, it has enabled the engineering capstone teams to work with students in six other colleges over the past five years: Arts \& Architecture, Business, Communications, Earth \& Mineral Sciences, Health \& Human Development, and/or IST. To date, most of these cross-college partnerships entail only two colleges (and usually multiple engineering majors), but some teams involving three collegesBusiness, Engineering, and IST_-have been successful in completing a capstone design project for an industry sponsor while simultaneously satisfying the course requirements for students in all three colleges. ${ }^{7}$ It is on this successful track record of partnering students across engineering and non-engineering colleges that we undertook the Creative Campus project as a chance to integrate students and faculty in engineering with the arts as many others have done in their capstone design $^{9,10,11,12}$ and related technical courses. ${ }^{13,14,15}$ 


\section{The Creative Campus Initiative and Penn State's The Secret Life of Public Spaces}

The Creative Campus initiative began in 2004 following a two-day meeting to examine the characteristics of the projects, proposals, curricula, and "creative forces" that enable effective partnerships in education and the arts. ${ }^{16}$ In 2006, the Arts Presenters established the Creative Campus Innovations Grant Program with funding from the Doris Duke Charitable Foundation to enable "exemplary campus-based performing arts presenters to develop and implement programs and strategies beyond conventional practice that integrate their work across the academy." "17 Based on the success of its initial eight grants, funding was renewed in 2008 to award six more grants, ranging from $\$ 100,000-\$ 200,000$, for one-year and two-year collaborations between administrators, faculty, and staff in academia with local community partners. Each project is required to: (a) integrate the performing arts into the education, service, and scholarly missions of the academy and engage chief academic officers and executive leadership; (b) provide opportunities to deepen and expand the participation of artist(s) in the academy through long term residencies, commissions and/or other creative activities; and (c) identify, document, and share lessons learned that will contribute to an evolving knowledge base and learning community for campuses and the wider performing arts and presenting field. ${ }^{17}$ This paper focuses on how we accomplished (a) in partnership with the Learning Factory while also addressing (c) by sharing relevant lessons learned for other capstone design programs.

Unsuccessful in its 2008 attempt, Penn State's Center for Performing Arts was one of the six awardees in 2010. The project, entitled The Secret Life of Public Spaces, examined the interplay between people, objects, and spaces through a cross-campus interdisciplinary residency/creation program involving faculty, students, and staff at Penn State and Los Angeles-based Diavolo Dance Theater (www.diavolo.org). The project team was led and coordinated by the Center for Performing Arts and engaged faculty in the College of Arts \& Architecture (Architecture, Dance, and Landscape Architecture departments) and College of Engineering (Mechanical Engineering, Industrial Engineering, and SEDTAPP). Secondary partners in the project included the H.O. Smith Botanic Gardens in the Arboretum at Penn State and the E-Learning Institute in the College of Arts and Architecture with program assessment performed by a faculty member from the College of Education. The team received a \$200,000 grant from the Doris Duke Charitable Foundation, and cost matching (both in-kind and financial support) from departments, centers, colleges, and the university more than doubled the size of the award.

Penn State's Creative Campus project proposed to use a multi-disciplinary, action-research project to invigorate public space. Public space is the theatre of everyday life, but everyday patterns usually slip into invisibility and are lost. The Secret Life of Public Spaces entails a rediscovery of movement (people), topography (space), and devices (objects), based on inquiry and artistic performance, to reveal and recast the everyday dynamics of public spaces. Student performances build on the interplay of movement and objects, which is central to Diavolo's own performances. Explorations of community and campus spaces introduces a third elementtopography - to inspire and challenge Diavolo to bring active topography to the theater stage. The project website (creativecampus.psu.edu) provides detailed information on the team collaboration, the design research and dance development, and highlights from the two-year project, which concluded in April 2012. Diavolo's resulting performance, Transit Space, is also discussed online (http://www.diavolo.org/transit_space.html). 


\section{Capstone Design Projects for Creative Campus}

While other universities have successfully used the Creative Campus initiative to spur creativity in introductory engineering course ${ }^{18,19}$ and introduce engineering to non-majors, ${ }^{20}$ our goal was to use capstone design projects to integrate engineering students into artistic performances. Our Creative Campus project proposed 3 capstone design projects to realize the interplay between people, objects, and space proposed for the The Secret Life of Public Spaces. After receiving notice of the award in October 2010, the team began discussing themes for performances and reviewing the structures used in Diavolo's work. Unfortunately, a unifying theme had not yet emerged by the end of the Fall semester, making it difficult to specify a capstone design project for the spring semester as proposed. After some last minute brainstorming, a capstone project idea was developed to have a team of engineering students investigate a portable and low-cost motion capture system that could be used to record and analyze movement in public spaces. The hope was to develop a system that might help us "see" some of the secret lives of public spaces, which might then inform the design of objects or choreography for future performances. The details on this first capstone design project follow along with reflections from the faculty "client". Discussions of the other two capstone design projects, which both involved "dance vehicles” that emerged in the second year of the grant, follow in subsequent sections.

\subsection{Spring 2011 Capstone Design Project: A Portable, Cost-Effective Motion Capture System}

The objective in this first capstone design project was to design a portable and cost-effective system to capture people's movement through different public spaces on/near the Penn State campus. The intent was to design a system that could capture the gross/macro-level movements of people through a large open space, not necessarily the fine/micro-level movements of individuals. The system also needed to be easy to set up, move, calibrate, and analyze the recorded data. To accomplish these goals, the team was asked to perform the following tasks:

1. Review and catalogue the pros/cons of existing motion capture systems

2. Visit the three venues on/near campus to examine the topography and general motion of people as they move through these spaces

3. Develop 10+ concepts for motion capture systems that could be used in these venues

4. Meet with relevant faculty in Architecture, Landscape Architecture, and Dance to review these ideas and down-select to 2-3 ideas for further development

5. Refine and prototype 1-2 ideas and review them with relevant faculty in Architecture, Landscape Architecture and Dance to the most promising concept

6. Create a working prototype and demonstrate its use in at least two of the venues At the end of the semester, the team was required to deliver the working prototype along with a detailed report of their findings, ideas, and design process. Students were also encouraged to participate in 1-2 project reviews with the larger Creative Campus team over the course of the Spring semester as the project was evolving quickly by this point. Finally, we announced that one engineering student from the team would have the opportunity to travel to L.A. to visit Diavolo in June 2011 to help present the team's ideas and its capabilities, if desired.

Although the project description appeared like any other capstone design project, students were not sure what to make of the faculty member from Architecture that was serving as the "client" for the project. This was the faculty member's first experience with a capstone design team and first experience working with Penn State engineering students. The faculty "client” had worked with engineers professionally on a number of design projects and was under the impression that 
engineering primarily wanted to facilitate and improve a design through engineering, not engage in the "artistic" creation of something new. The engineering team fulfilled that preconception, as they struggled with the fact that the project did not have a clearly defined problem and that the goal for the project/video filter, was vaguely, "a way to look at crowds”. The faculty member likened the project to making something akin to a tool for artists that had multiple capabilities without knowing how it might actually be used. This was incredibly frustrating for the team; however, they quickly became focused on developing something that simply met the parameters spelled out in the project description, and they did not seem interested in its larger potential for the Creative Campus project.

As the semester progressed, the students knew far more about the technology than the faculty "client" did; however, the faculty faced a constant struggle to have the team "show the potential of the technology and what was possible”. The team worked as compartmentalized experts with sponsor-team meetings focusing on answering specific questions or responding to suggestions from the faculty "client". Very little brainstorming occurred during any of these meetings, which the faculty member tried to make less formal and more conversational similar to the studio environment used in architecture. On the positive side, the team worked very efficiently, and the corresponding hierarchy within the team made communication very direct; however, the faculty member felt that the work could have been realized in a stronger way. Again, drawing on the studio model used in architecture, students' work is improved through critique, participation, and contribution, and the faculty member found it difficult to play "client" and not be a co-designer or stronger mentor to the capstone students.

This team was often stymied by a lack of "real world" in the project. Even though Diavolo and the grant were discussed at length, some members on the team felt "second-class" because they were still working for a faculty member in the confines of the university. Interestingly, while the project was available to students in computer engineering, electrical engineering, industrial engineering, and/or mechanical engineering, the team consisted of five computer engineers, and none of them had listed this project as their first choice. The team did not become fully engaged and take ownership in the project until about Week 12 when they took their prototype, which they had been testing by videotaping a single person in a small retail-like space, into a large open public space and started taking video. It was the first time that they talked about the various potentials for the motion capture system, and the first time they discussed things like colorcoding and people-counting with the faculty "client". It was at this point that the team dropped started "behaving like confident thinkers/makers/engineers".

The real success - and irony of the project - is that the engineering students were reluctant to participate in anything they deemed "artistic", yet in the end they created something with a lot of "artistic" potential. Their system provided a successful way to visualize/record crowds and movement in public space using any hand-held digital camera. Figure 2 shows screenshots of the video that can be captured along with different filters that can be applied to visualize the motion. The team was awarded $2^{\text {nd }}$ Place Best Project at the Spring 2011 Design Showcase from among the 84 capstone projects that were judged by industry representatives at the showcase. When asked why they thought they had won, the team felt that their project was more dynamic, visual, and colorful than "typical Capstone projects". 


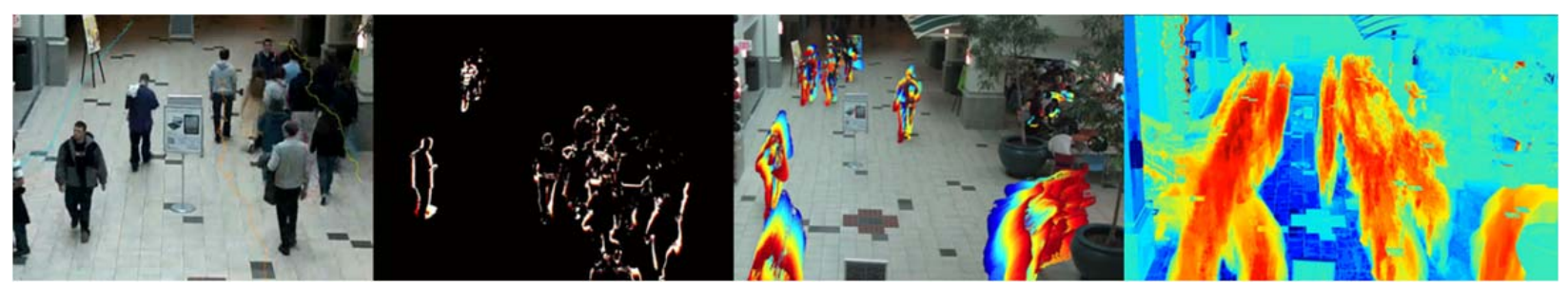

Figure 2. Screenshots from the Motion Capture System Capstone Design Project

\subsection{Fall 2011 Capstone Design Project: Dancing on Air}

As the Creative Campus performance become more clarified during a week-long intensive visit of faculty and students with Diavolo in Los Angeles, the capstone design project for Fall 2011 was captured by the phrase "Dancing on Air", and a faculty member in Dance served as the "client" for this project. The "client" was interested in having the dancers be suspended or elevated off the ground in some manner. The idea stemmed from her previous use of stilts in dancing; however, the "client” avoided using terms like "stilts" so as not to bias the students' thinking. Rather, the "client” was interested in how dancing was altered, enhanced, or even prevented when a dancer cannot directly touch the ground. Diavolo uses large props and devices in their work; so, the precedent to have a large apparatus in the Penn State performances had been set, and the hope was to have a capstone design team help create an answer.

Therefore, the objective of the second capstone project was to design, engineer, and develop a means of conveyance for the dancers to move through three specific public spaces on/near campus at an elevated height of 1-3 ft. The team's solution needed to support an individual dancer "moving through the air", but the team was given flexibility to consider solutions that conveyed multiple dancers simultaneously. Whatever the result, the team's solution had to work on any terrain (e.g., grass, sidewalk, pavement, packed dirt, slope, hill) and in an open area. It also needed to be easy to transport, require minimal set-up, and need no assistance from other dancers when in use. Specific tasks for the team were:

1. Review existing solutions for conveying dancers above the ground

2. Review the topography of the three specific spaces on/near campus

3. Brainstorm ideas to accomplish the desired effect

4. Obtain feedback from the project sponsors and dancers

5. Refine and prototype 2-3 ideas and review them with the project sponsors and dancers

6. Create final prototype(s) of the best solution that can be used by the dancers The capstone design team was also required to participate in 1-2 project reviews with the entire Creative Campus team over the course of the Fall semester and present their ideas to members of Diavalo during their visit to Penn State during the Fall semester. At the end of the semester, the team had to deliver their final prototype(s) along with a detailed report of their findings, ideas, and design process along with detailed part specifications for their solution.

The reception to this project was very different at the Project Kickoff compared to the first one. A large number of students spoke with the "client" at the Project Kickoff and were intrigued by how different the project was from a typical capstone project and how their part in the project would be a "less traditional" role. The problem presented was quite different from the other capstone projects in that students were being asked to work in an unconventional process by 
becoming creative partners on the project. Their input was essential, and this resonated with the students who wanted to make an impact through their capstone project.

The capstone team comprised four mechanical engineering students, many who selected this project as their first choice. The project was assigned to a mechanical engineering section not because a mechanical solution was envisioned, but rather because a mechanical engineering faculty member was very excited to supervise this project-another unexpected surprise to our Creative Campus team. The students were very eager to engage in the process, and even though they were not quite sure what to expect, they jumped in and committed completely. None of the engineering students had any prior experience with dance, and so the "client" asked the team to spend a good deal of time looking at videos and pictures of dance using props and apparatus to find inspiration. The students were very fascinated with the idea, and they rose to the challenge even though they had clearly been pushed out of their comfort zone by being pushed to think about engineering in an entirely new way.

A team of dancers was also assigned to work closely with the engineers on the capstone design team. The capstone students attended dance rehearsals and the working sessions that started to take shape in IdeaLab, a three-hour interdisciplinary design studio that met weekly starting in Fall 2011 to help align faculty and students involved with the Creative Campus project. The capstone team developed numerous ideas and models, and the interactions with the dancers and faculty "client" really inspired the engineering students to be involved in creative play and thinking outside the box. This idea of play became central to the students' ideas for the project.

After a critical review of their ideas with Diavolo during an on-site visit in November 2011, the team pulled together all of the elements that the engineers and the dancers had decided were essential to create an environment that would allow the dancers to move while being suspended above the ground. As the design evolved, it became a "dynamic dance stage" that the dancers' movement caused to locomote in space. As seen in Figure 3, the "stage" consisted of a 3x3 grid, and inside each of the nine spaces was cube, about 2 feet per side, held up at different elevations by a steel crankshaft. Each box moved up and down as the weight of the dancers actuated it, which in turn, rotated the crankshaft. Each crankshaft was attached to a set of wheels, and as the crankshaft turned, the wheels rotated to create lateral movement of the stage. Thus, as the dancers moved across the top, the boxes moved up and down, causing continuous elevation changes of roughly one foot while the entire stage translated left and right.

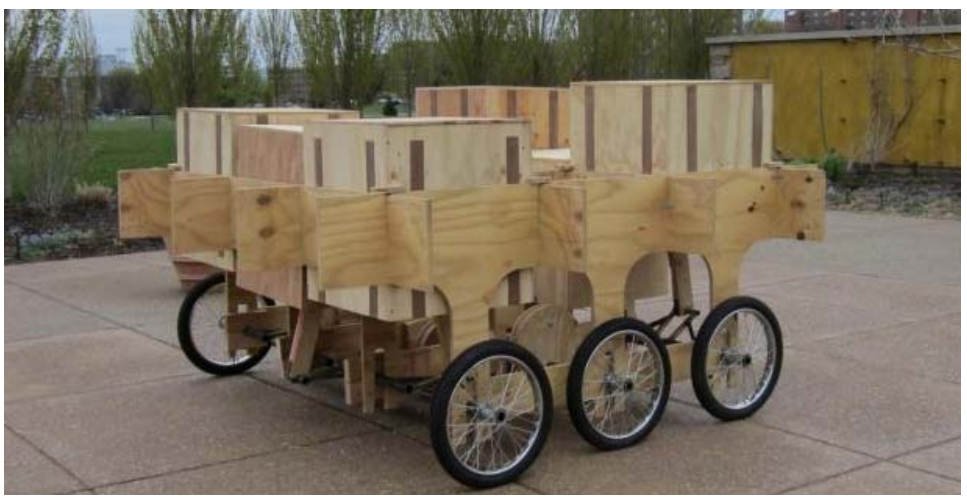

Figure 3. The Capstone Team's Dynamic Dance Stage Awaits Use by the Dancers 
In retrospect, the scope of this capstone design project may have been overambitious for a single semester, but the engineering students worked tirelessly and made a great showing at the Design Showcase. One of the more successful aspects of the project was the exchange between the two disciplines as the engineering students were constantly challenged be a bit artistic in the process and to think and respond in ways akin to the real world. The final design was chosen because it most effectively used the engineering students' abilities to enhance the themes and choreography of the performance. As one dancer noted:

"The most rewarding part of this project was the final show at the Arboretum when our Dance Vehicle 02 finally worked. We showed up to the Arboretum early to fix some things because it hadn't been working correctly the day before. It was the first time our little machine had been out of the shop yard and we actually had room to push it, and it was a huge hit at the show. We had a big crowd of people around and they would cheer when it worked and sigh when something went wrong. It was great to see the enthusiasm, especially because we had it in full working order by the end of the night. Although dancing on top of it was frightening, it was a huge breakthrough and I look forward to working on it in the future."

Audience feedback from the performance noted how much one could learn about the complexity of design by watching the students use the dance vehicle.

3.3. Spring 2012 Capstone Design Project: Improving the Transmission of a $12 \mathrm{ft}$ Dance Vehicle The third capstone design project for the Creative Campus project involved redesigning the transmission for a larger dance vehicle that emerged from the interdisciplinary design studio, IdeaLab, in Fall 2011. Shown in Figure 4, the dance vehicle allows people to walk in two 12foot diameter wheels thereby creating a large, moving structure that can navigate open terrain while also provide an isolated space for dancers to perform inside the vehicle, namely, the "cage" interior to the wheels as seen in the figure. The objective for the engineering capstone design team was to improve the gearing system and transmission elements between the wheels and the internal structure of this vehicle to reduce friction and make it safer and more robust. The prototype in Figure 4, along with a $1 / 4$-scale model of the vehicle, was made available to the capstone design team. The team had to work quickly as the new dance vehicle had to be ready the first week of April (Week 11 in the semester) to allow time for rehearsal before the outdoor performances and Diavolo's visit in mid-April 2012. At the end of the semester, the team had to deliver a detailed report, including CAD models, relevant analyses, and detailed specifications of the redesigned gearing and transmission, and present their results at the Design Showcase.

Noting the disconnect between the Fall 2011 capstone team and the rest of the Creative Campus effort in IdeaLab, the Spring 2012 capstone design team was strongly encouraged to join the other students in IdeaLab each week, which was scheduled for Friday evenings from 6-9pm, and at least one representative from the capstone design team was required to attend these meetings regularly to provide updates to the other students and faculty. A faculty member in Architecture served as the "client" sponsoring the project. This faculty member had overseen development of the vehicle prototype in fall and could facilitate logistics as further construction was to proceed in the building yard outside of the architecture department due to its size. Construction of the full-scale prototype shown in Figure 4required using over two-thirds of the available outdoor building space during its fabrication. 


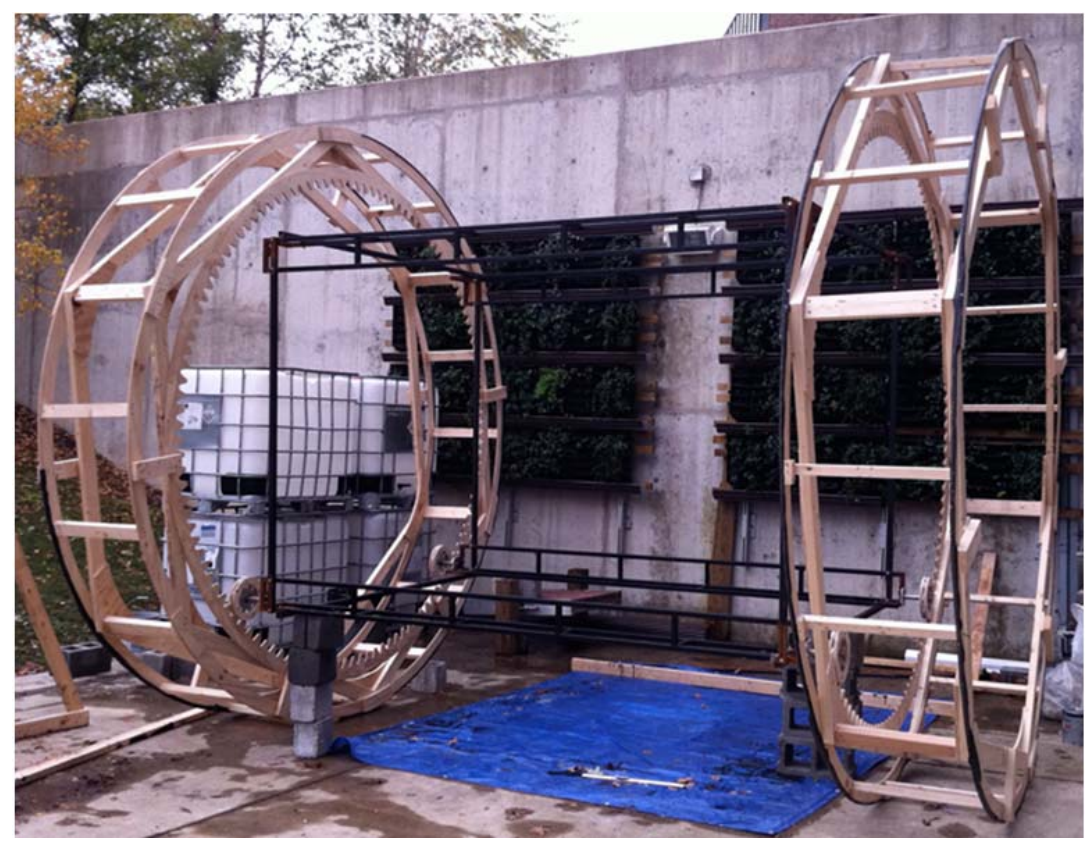

Figure 4. Initial Full-Scale Prototype of Dance Vehicle (Fall 2011)

The capstone team consisted of five mechanical engineering students who partnered with four architecture students and six dancers on the project, creating a very large multidisciplinary team. This created considerable barriers: class schedules, learning styles, formalities between student and "teacher" in various departments, shared vocabularies with very different meanings and implications, and different work ethics and expectations. The end result was that there where many times during the project where the engineering students had to work outside their comfort zone. They spent a considerable amount of time working in the architecture department building and building yard, and they were forced to work in a studio-like environment. This meant that their work and ideas were subject to architectural critique-like situations, where a group is working towards the best possible idea, solution, or design through critique. With this group of students, the working environment was very critical and not always polite. Design in the architectural context does not mean one solution (arrived at through reduction and elimination), but a variety of solutions, each with pros and cons. The goals of the project evolved as the work progressed and expanded to address many potentials, instead of focusing on doing one thing or solving one particular problem. The engineering students got frustrated by the larger group's focus on the "look" of their work and the "craftsmanship" of their components, bends, etc., but they handled the feedback well. For instance, when one of the large diameter wheels broke before the engineering students could present their work at the Design Showcase, the engineering students wanted to fix the problem by welding a large brace on the wheel so that it could be moved. The non-engineering students convinced them to make a gig, re-bend the broken wheel, and fix it so that the overall aesthetic of the vehicle remained uniform. It was a great illustration of design priorities for the capstone team: the engineering solution would have gotten the wheel rolling, but the design solution insisted that the vehicle also "look good".

The faculty "client” also noted many differences in how digital modeling and rendering were used in engineering versus architectural environments. The engineering students did not see value in making physical (architectural) models of the vehicle while the architecture students felt 
that the digital models/renderings from the engineering students failed to express the "space" of the vehicle and were "inaccurate". Both groups of students did work in concert however. The architecture students made several $1 / 4$-scale models on the laser cutter, each one different in terms of truss design, cage configuration, etc. The engineering students would then "build" the models in SolidWorks and analyze them. Despite the efforts to design using these models, building the final vehicle full-scale was the ultimate model, and at one point the team realized that they could eliminate half of the steel struts in each wheel, which they did not realized from earlier models. Finally, everyone was shocked by the speed and force with which the final vehicle moved, having created something far more complex and complicated than anyone anticipated. Dancer safety immediately became a concern, and Diavolo's expertise working with large structures became critical in ensuring a thoughtfully choreographed performance that kept everyone safe and out of harm's way. This was something that no one on the team had considered previously.

The team received $2^{\text {nd }}$ Place Best Project at the Spring 2012 Design Showcase from among the 94 capstone projects that were judged by industry representatives at the showcase, and the Dean of Arts \& Architecture singled-out the team's efforts during her keynote speech at the Industry Partners' Dinner that followed the showcase that spring. Many factors contributed to the success of this project. First, it was a public project, made in a fairly open space. As a result, there was a lot of contact with outsiders and students from across campus as people drifted in and out of the work zone. The team had to do their part as spokesmen for the larger project; they could not work in isolation as the vehicle was not hidden in a shop or boardroom. Second, the "product" was fun-everyone who worked on the project wanted to play on it. The joy that people got from using the vehicle was a highlight to the design/engineer/build team. Third, the team knew the end users (i.e., the dancers) as they were integral in the vehicle's development. The team knew the dancers and had spent time with them and Diavolo, although some of the engineering students felt that collaboration with the dancers amounted to them "just wanting a vehicle to dance on by this date". The final public performance (see images in Figure 5) drew a crowd of more than 400 people, nearly double what was expected. This turned the team into public figures as everyone wanted to know who was responsible for the vehicle. The team was both surprised and delighted by the impact of the event and their project.

Finally, one thing that all of the students suffered from on this capstone project was a lack of foresight. The design project was structured so that faculty research and pre-project prep would guide/facilitate the work, not dictate the final results. This working method allowed for a great degree of student input (far greater than any other capstone deign project), but it also meant that students were operating with reserved confidence and expectations. In the end, there was a good degree of original/inventive design, but stereotypes of engineers and artists prevailed. The engineering students craved structure and focus, and the architecture and dance students saw structure and focus as limitations or reducing artistic freedom too early. These groups had very different tolerances for indeterminancy, which gets at the root of what separates design from problem solving, an important lesson for everyone on the project. 


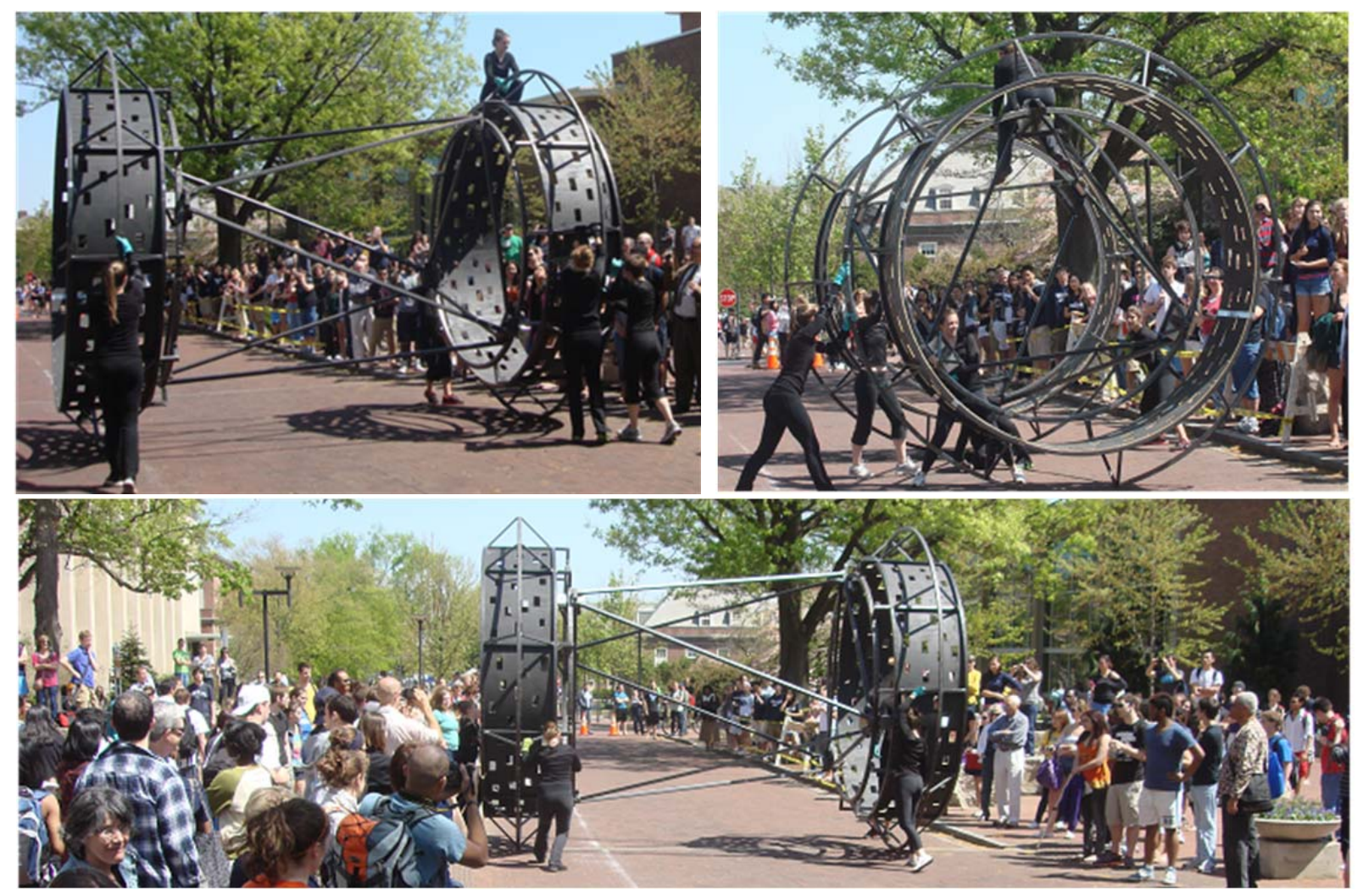

Figure 5. Images from the Public Dance Vehicle Performance

\section{Student Feedback and Evaluation}

At the end the Spring 2012 semester, a final survey was administered by the project evaluator, a faculty member in Education, to the 59 students involved with the Creative Campus project. Thirty-six people responded (a response rate of 61\%), and responses were evenly divided among dancers (10), designers (14), and engineers (12). One section of the survey dealt directly with learning and another section focused on the overall perceived impact of the study on participants.

Overwhelmingly (with only one survey respondent dissenting), students believed that the Creative Campus project allowed them to work with people they otherwise would not have met in their student experiences. They also clearly recognized that many of these people think differently than they do. The key interdisciplinary learning environment was posited to be the Idea Lab and about two-thirds of respondents recognized this, with designers providing the highest level of agreement (79\%). Three-quarters of the respondents agreed that the project provided an example of "action research"; however, when asked if inquiry/research was as important as performance, designers almost unanimously agreed (92\%), but dancers were clearly split (50\%), and engineers agreed at a rate of 70\%. No group majority was inclined to rate the project as an example of "teaching and learning at its best," but between 60 and 80 percent said they would rate the project as one of their top learning experiences in college. Interestingly, the groups that tended to rate lower across most categories changed positions when asked if the project allowed them to work with faculty in ways not experienced in the classroom (dancers, 100\%; and engineers, 92\%). When asked if they would work on an interdisciplinary project like 
The Secret Life of Public Spaces again, 85\% of designers and engineers said yes, but only 50\% of dancers indicated that they would be so inclined.

In terms of impact that would affect future learning, about $40 \%$ of the dancers and designers believed that the project changed their perception of art and design, but $71 \%$ of the engineers reported a shift in perspective. However, all respondents agreed that the project had allowed them to reimagine the possibilities of art and design in public spaces. Overall, a majority of the student respondents did not believe that the project had a significant impact on the campus community despite the high audience turn-out for the performance (over 1000 people attended the three public performances by the students). Some of the negativity revealed by the survey contrasted with what was interpreted as minor disappointments but ultimate satisfaction in reflection papers submitted by students in IdeaLab. The dancers were the most negative, and this may have been due to a number of factors, the primary one being that they believed that "deliverables" had not been forthcoming or available for them to adequately choreograph or rehearse. One dancer interpreted this as "unfair" in that dancers saw themselves responsible to the public to come up with "something cool". Without structures to practice with, it was difficult to create a performance.

In terms of faculty learning, it is more difficult to discern. The project began by employing a process familiar to the design faculty in architecture - an extended period of brainstorming, selfregulated inquiry, and sharing of what was learned during that inquiry. Other faculty appeared to willingly go along with this process. From a substantive perspective, the inherent elements of the project—public space, structures and machines, movement—individually aligned with previous research interests for both design and dance faculty, many of whom were pre-tenure at the start of the project. However, the intersection of these elements did not seem to appeal equally to all and was in fact foreign to some of the engineering faculty involved in the project. In addition, there seemed to be different views and practicalities influencing how the faculty/student roles played themselves out during the project. Some faculty seemed to see research as personal exploration and left students alone to explore; others saw a need to scaffold both understandings and procedures for doing research and stood as facilitators on the sidelines until individual projects gained their own impetus and direction. The engineering faculty presented a different research stance with one first insisting then later encouraging students to comport to a specific ideal (social and economic value), and the other seeing research possibilities in the pedagogy afforded by having non-engineering faculty serve as "clients" for the capstone design projects. These views are certainly not comprehensive to the experience and, because of the numerous sub-projects and lengthy time period, served to both facilitate and impede project goals. These differing views of the relationship of the project to one's scholarly research appeared further removed from the project as it neared its completion.

\section{Closing Remarks and Ongoing Collaborations}

Penn State's Creative Campus project was successful in bringing together students and faculty in ways many were not used to working together. Architects are designers, somewhat unused to having their designs fabricated into full-scale reality. Engineers are used to having a clearly defined problem to "solve" through careful analysis and execution. The Secret Life of Public Spaces brought together these two groups with a third group, artists, to collaborate in ways none had previous experience in doing. The arts served as the catalyst for the project performances, 
with each discipline inventing new ways of seeing their own work, with what, for them, was an usual end goal: a public performance.

The Learning Factory's role in the Creative Campus project was essential in bringing the theoretical and the imagined into reality. Providing a place and a means by which to bring one's designs to life was a critical part of the overall project. Working in the the Learning Factory and providing critical feedback for the capstone team was also aided Diavolo in their own creative process. Diavolo has a fabrication studio similar to the Learning Factory in Los Angeles, and they were impressed at the resources available for students and faculty provided by the Learning Factory. The meetings with Diavolo were among the highlights of the Creative Campus project and provided critical inspiration for the students faculty, often at just the right time.

Working with faculty "clients" instead of industrial sponsors for capstone design projects had benefits as well as shortcomings. It provided a means to strengthen collaborations across the colleges, but some engineering students felt shortchanged that their sponsor was not from industry. In retrospect, the students should not have listed a non-industry-sponsored capstone design project among their top five preferences as no student was forced to work on any of these projects and all had time to meet with the faculty "client" during the Project Kickoff. The engineering students did their best to reconcile the requirements for their capstone course with the "open-endedness" of the project itself. Many struggled to respond to the dancers and architects wanting more "abstract ideas...more aesthetics" or understand how something could be "elegantly engineered", a term none of the engineering students encountered in their four years of engineering coursework. While tensions often ran high among the students and faculty "clients" from aligning class schedules to overcoming language barriers and stereotypes while accommodating different design pedagogies (e.g., architectural studio and critiques versus a more structured product development process), all three capstone teams achieved successful project outcomes, with two out of the three receiving Best Project awards as judged by industry. We will continue to monitor students' progress when possible to evaluate the long-term impact of their involvement with Creative Campus on their academic and professional success.

The interdisciplinary collaboration continues to bear fruit at Penn State, having established successful partnership across the College of Engineering and College of Arts \& Architecture. The Center for Performing Arts created a Faculty Think Tank to nurture more cross-disciplinary collaborations with the arts. The group meets 2-3 times per semester to discuss collaborative projects for which they were seeking partners, as a way to foster more integration of the arts into various disciplines. Faculty from dance, theater, engineering, english, information science and technology, women's studies, the art museum, the center for teaching excellence, the University Fellowships program, and several others have self-selected to join this consortium. Meanwhile, faculty in the visual arts have become formally engaged in funded research projects with several engineering faculty based on the relationship established through the Creative Campus project, and a new dual-degree graduate program and inter-departmental Ph.D. programs in design that span engineering and multiple disciplines in Arts \& Architecture (and other colleges) are also in discussion. 


\section{Acknowledgements}

This project was made possible, in part, by a grant from the Association of Performing Arts Presenters Creative Campus Innovations Grant Program, funded by the Doris Duke Charitable Foundation. Any opinions, findings, and conclusions or recommendations expressed in this paper are those of the authors and do not necessarily reflect the views of the Association of Performing Arts Presenters or the Doris Duke Charitable Foundation.

\section{References}

${ }^{1}$ Pembridge, J. and Paretti, M. C., "The Current State of Capstone Design Pedagogy", ASEE Annual Conference \& Exposition, Louisville, KY, ASEE, 2010, AC 2010-811.

${ }^{2}$ Howe, S., Lasser, R., Su, K. and Pedicini, S., "Content in Capstone Design Courses: Pilot Survey Results from Faculty, Students, and Industry", ASEE Annual Conference and Exposition, Austin, TX, ASEE, 2009.

${ }^{3}$ Dawson, J. and Kuchnicki, S., "Experiences of Using Formula SAE as a Capstone Design Project", ASEE Annual Conference \& Exposition, Louisville, KY, ASEE, 2010, AC 2010-79.

${ }^{4}$ National Academy of Engineering, 2012, Infusing Real World Experiences into Engineering Education. Washington, D.C., http://www.nae.edu/65099.aspx.

${ }^{5}$ Lamancusa, J. S., Jorgensen, J. E. and Zayas-Castro, J. L., "The Learning Factory-A New Approach to Integrating Design and Manufacturing into the Engineering Curriculum," Journal of Engineering Education, Vol. 86, No. 2, 1997, pp. 103-112.

${ }^{6}$ Lamancusa, J. S., Zayas, J. L., Soyster, A. L., Morell, L. and Jorgensen, J., "The Learning Factory: Industry-Partnered Active Learning," ASEE Journal of Engineering Education, Vol. 97, No. 1, 2008, pp. 5-11.

${ }^{7}$ Simpson, T. W., Kisenwether, E. and Pierce, G. R., "Driving Entrepreneurial Innovation through the Learning Factory: The Power of Interdisciplinary Capstone Design Projects", ASME Design Engineering Technical Conferences - Design Education Conference, Portland, OR, ASME, 2013, Paper No. DETC2013/DEC-12492.

${ }^{8}$ Graham, R., 2012, Achieving Excellence in Engineering Education: The Ingredients of Successful Change. London, UK, The Royal Academy of Engineering, http://www.raeng.org.uk/change.

${ }^{9}$ Pidaparti, R. M., "The Art of Engineering in Capstone Design", ASEE Annual Conference \& Exposition, Salt Lake City, UT, ASEE, 2004, AC 2004-291.

${ }^{10}$ McGrann, R., Mackiewicz, G., Walsh, J., Williams, K., Griffin, J., Hobbs, Y. and Crocker, M., "Capstone Design: Sculpture and Structure", ASEE Annual Conference \& Exposition, Portland, OR, ASEE, 2005, AC 2005-1250.

${ }^{11}$ Wang, J., Liu, S. and Price, A., "The Dancing Marionette - An Interdisciplinary Capstone Design Experience for Engineering Technology and Computer Science Students", ASEE Annual Conference \& Exposition, Chicago, IL, ASEE, 2006, AC 2006-1713.

${ }^{12}$ Heng, I. H., Zhang, A. and Zia, R., "A Novel Approach in Teaching STEM Subjects through Cross-Departmental Collaboration in Capstone Courses", ASEE Annual Conference \& Exposition, San Antonio, TX, ASEE, 2012, AC 2012-3129.

${ }^{13}$ Hertzberg, J. and Sweetman, A., "A Course in Flow Visualization: The Art and Physics of Fluid Flow", ASEE Annual Conference \& Exposition, Salt Lake City, UT, ASEE, 2004, AC 2004-230. 
${ }^{14}$ Irwin, J. L., Wanless, D., Sanders, P. and Wagner, S. W., "Engineering Technology Interdisciplinary Projects", ASEE Annual Conference \& Exposition, San Antonio, TX, ASEE, 2012, AC 2012-5035.

${ }^{15}$ Vuksanovich, B. D. and Wallace, D. R., "Evaluation of STEM+Art Collaboration for Multidisciplinary Engineering Technology Laboratory", ASEE Annual Conference \& Exposition, Vancouver, British Colombia, Canada, ASEE, 2011, AC 2011-1938.

${ }^{16}$ Fisher, R. W. and Mortimer, D. H., "The Creative Campus: The Training, Sustaining, and Presenting of the Performing Arts in American Higher Education", 104th American Assembly, Harriman, NY, Columbia University, 2004, http://creativecampus.org/docs/cc_american.pdf.

${ }^{17}$ Benson, L., 2012, Creative Campus Website. Washington, D.C., Association of Performing Arts Presenters, http://www.creativecampus.org.

${ }^{18}$ Burkett, S. L., Lusth, J. C. and Kotru, S., "Creativity in an Introductory Engineering Course", ASEE Annual Conference \& Exposition, Vancouver, British Colombia, Canada, ASEE, 2011, AC 2011-1481.

${ }^{19}$ Burkett, S. and Snead, C., "Picasso's Clarinet: When Art and Engineering Collide", ASEE Annual Conference \& Exposition, Austin, TX, ASEE, 2009, AC 2009-32.

${ }^{20}$ Anderson, M., Todd, B., Burkett, S., Warren, G., Brown, M. and Cordes, D., "Engineering Collaborations with Liberal Arts", ASEE Annual Conference \& Exposition, Austin, TX, ASEE, 2009, AC 2009-1801. 